\begin{tabular}{lcl}
\hline Bentham OPEN & The Open Nursing Journal & $\begin{array}{l}\text { The } \\
\text { Open Nursing } \\
\text { lournal }\end{array}$ \\
\hline CrossMark & Content list available at: www.benthamopen.com/TONURSJ/ & DOI: $10.2174 / 1874434601610010036$ \\
\hline
\end{tabular}

\title{
Editorial
}

\section{Innovations in Mental Health Care}

The traditional means of providing mental health care (e.g. delivered in psychiatric facilities in face to face format) are not meeting many patient needs. The World Health Organization's (WHO) Mental Health Action Plan [1] lists two key objectives for improving mental health care: integrating mental health care into community settings and strengthening information technology. Patients are more likely to see their primary care providers for their psychiatric symptoms, leave psychiatric care due to fear of stigma [2] and may prefer alternative treatment options for their mental illness. As an Advanced Practice Nurse in Psychiatry, I see patients for medication management who sometimes leave treatment for these same reasons. My practice does not have integrated primary and mental health care AND we do not conduct video or telephone appointment with patients. These deficiencies ultimately affect patients' mental health. The increased use of technology by patients needs to drive all health care delivery systems to develop innovative methods for improving individuals' access to mental health care and overall social functioning. I am happy to share some new ideas for mental health care delivery in this special issue. This thematic issue includes review and research articles addressing the two WHO mental health care objectives. Three articles describe primary care providers as avenues to improve access to mental health. Patients' access to mental health services can be problematic due to limited providers. Kverno describes a new education program to increase the number of mental health nurse practitioners in rural environments by targeting primary care nurse practitioners living in these environments and training them to be psychiatric mental health nurse practitioners. McIntosh, Startsman and Perraud reviews the issue of integrated mental health care (combining mental health and somatic medicine) and its implications for a new role in nursing practice. Kriebel-Gasparro discusses how advanced practice nurses can play a significant role in bipolar disorder screening in primary care. The other three articles examine potential interventions to engage and prevent mental illness sequelae: phone technology (Duarte \& Thomas), humor use for substance abuse treatment (Canha) and evidence based mindfulness based interventions for at risk adolescents (Rawlett \& Scrandis). These articles can lead nurses in clinical practice and research to expand their thinking to improve mental health care and access using ideas different from the historical care delivery system. It is my hope this issue will open a dialogue to address the pressing mental health needs of our global community.

\section{REFERENCES}

[1] World Health Organization. Mental health action plan 2013-2020. Available from: http://www.who.int/mental_health/publications/action _plan/en/ 2013.

[2] Newman D, O'Reilly P, Lee SH, Kennedy C. Mental health service users' experiences of mental health care: An integrative literature review. J Psychiatr Ment Health Nurs 2015; 22: 171-82.

Debra A. Scrandis University of Maryland School of Nursing Baltimore, MD 